\title{
Avaliação do extrato etanólico de Ottonia martiana Miq. para o controle de duas doenças florestais
}

\author{
CUNICO, M.M. ${ }^{1 *}$; AUER, C.G. ${ }^{2}$; CÔCCO, L.C. ${ }^{3}$; YAMAMOTO, C.I. ${ }^{3}$ MIGUEL, M.D. ${ }^{4}$; MIGUEL, O.G. ${ }^{4}$; VIEIRA, G. ${ }^{1}$; \\ SANQUETTA, C.R. ${ }^{1}$ \\ ${ }^{1}$ Laboratório de Inventário Florestal, ${ }^{3}$ Laboratório de Análises de Combustíveis Automotivo, LACAUTets, ${ }^{4}$ Laboratório \\ de Fitoquímica, UFPR, Avenida Prefeito Lothário Meissner, 638, Jardim Botânico, CEP: 80210-170, Curitiba-Brasil \\ ${ }^{2}$ Embrapa Florestas, Estrada da Ribeira, km 111, Caixa Postal 319, CEP: 83411-000, Colombo-Brasil \\ *miriam@mcunico.com.br
}

\begin{abstract}
RESUMO: Metabólitos secundários presentes em plantas medicinais apresentam várias propriedades biológicas incluindo a atividade antifúngica. Esse estudo avaliou o potencial antifúngico da planta medicinal Ottonia martiana no controle da pinta-preta em erva-mate (Ilex paraguariensis) e do mofo-cinzento em eucalipto (Eucalyptus dunnii). Extrato etanólico (EBEtOH) dos órgãos totais (raízes, caules, folhas e frutos) foi preparado e testado na concentração de $1000 \mu \mathrm{g} \mathrm{mL}^{-1}$ contra os patógenos Cylindrocladium spathulatum (pinta-preta) e Botrytis cinerea (mofo-cinzento). Bioensaios in vitro (germinação de esporos e bioautografia direta) e in vivo (teste de patogenicidade em mudas) mostraram que o EBEtOH reduziu o crescimento micelial dos patógenos testados e a germinação dos esporos de $C$. spathulatum e estimulou a germinação de esporos de $B$. cinerea. O teste de patogenicidade mostrou que o controle da pinta-preta em erva-mate e do mofo cinzento em eucalipto não é viável usando-se a concentração testada de EBEtOH de O. martiana. Na bioautografia direta, foram detectadas zonas de inibição de crescimento micelial dos fungos e que foram relacionadas com a presença de piperovatina.
\end{abstract}

Palavras-chave: Botrytis cinerea, Cylindrocladium spathulatum, planta medicinal, proteção florestal

\begin{abstract}
Evaluation of Ottonia martiana Miq. alcoholic extract to control two forest diseases. Secondary metabolites from medicinal plants have several biological properties, including antifungal activity. This study evaluated the antifungal potential of the medicinal plant Ottonia martiana to control maté leaf spot (Ilex paraguariensis) and eucalypt gray mould (Eucalyptus dunnii). Ethanol extract (EBEtOH) of the total parts (roots, stems, leaves and fruits) was prepared at the concentration of $1000 \mu \mathrm{g} \mathrm{mL}^{-1}$ and tested against Cylindrocladium spathulatum (maté leaf spot) and Botrytis cinerea (eucalypt gray mould). In vitro bioassays (spore germination and direct bioautography) and in vivo bioassays (pathogenicity test in seedlings) showed that EBEtOH reduced the mycelial growth of the tested pathogens and the germination of $C$. spathulatum spores and stimulated the germination of $B$. cinerea spores. The pathogenicity test showed that the control of mate leaf spot and eucalypt gray mould is not viable using the tested concentration of $O$. martiana EBEtOH. Zones of mycelial growth inhibition were detected in direct bioautography and were related to the presence of piperovatine.
\end{abstract}

Key words: Botrytis cinerea, Cylindrocladium spathulatum, medicinal plant, forest protection

\section{INTRODUÇÃO}

A cada dia o mercado de produtos naturais vem crescendo de forma expressiva no mundo globalizado intensificando a pesquisa científica de plantas medicinais. Entretanto, a avaliação desse mercado promissor sob o prisma do desenvolvimento sustentável tem destacado a importância da aplicação da fitoquímica com enfoque multidisciplinar, a qual visa não somente o conhecimento do perfil fitoquímico da flora e a descoberta de novas substâncias, mas também a preservação e o conhecimento das propriedades biológicas das plantas (Maciel et al., 2002; Cunico et al., 2007).

Recebido para publicação em 10/12/2009

Aceito para publicação em 20/01/2012

Rev. Bras. PI. Med., Botucatu, v.14, n.3, p.464-469, 2012. 
Cabe ressaltar que os recentes avanços na química de produtos naturais têm contribuído para o conhecimento mais acurado da composição química das plantas, e permitem revelar a bioatividade de muitas substâncias naturais que interferem na germinação de sementes, no desenvolvimento de outras plantas e no crescimento de fungos (Cunico et al., 2007; Ferreira \& Rosa, 2009). Nesta perspectiva, destaca-se a busca por defensivos naturais (Stangarlin et al., 1999), visto que o uso indiscriminado e excessivo de agrotóxicos gerou crescente resistência de pragas, microorganismos fitopatogênicos e ervas daninhas, aos produtos sintéticos aumentando a dependência de insumos químicos por parte de produtores e impulsionando a indústria à descoberta e formulação de novos princípios ativos (Barbosa et al., 2009).

Os defensivos naturais podem atuar diretamente no patógeno, sobre a doença, ou ambos (Schwan Estrada et al., 2003; Silva et al., 2009). Outro aspecto é a exploração da atividade biológica de compostos secundários presentes nas tinturas ou em óleos essenciais de plantas que podem levar à indução de resistência, mais uma forma potencial de controle de doenças em plantas cultivadas (Santos et al., 2007; Vigo et al., 2009).

Diversas são as doenças causadas por fungos patogênicos em espécies cultivadas. Dentre essas, pode ser destacada a pinta-preta em ervamate (Ilex paraguariensis St. Hil.) causada pelo fungo Cylindrocladium spathulatum El-Gholl, Kimbr., Barnard, Alfieri \& Schoult. que é considerado um dos principais problemas provocando danos em mudas e árvores, e podendo induzir a mortalidade das mudas em viveiros florestais (Grigoletti Junior \& Auer, 2005). Outra doença importante é o mofo-cinzento em eucalipto (Eucalyptus dunnii Maiden) causado pelo fungo Botrytis cinerea Pers., uma das principais doenças em viveiro de eucaliptos, podendo causar morte de plântulas e lesões na haste e nos ponteiros de mudas já formadas (Krugner \& Auer, 2005).

A planta Ottonia martiana Miquel, família Piperaceae, é um arbusto que apresenta vários metabólitos secundários (Cunico et al., 2007), como amidas (piperovatina, isopiperovativa, piperlonguminina e isopiperlonguminina), esteróides ( $\beta$-sitosterol e estigmasterol), e óleos essenciais (cariofileno, espatulenol, $\alpha$-pineno, $\beta$-pineno, mirceno). Esta planta medicinal, presente na Floresta Atlântica, é utilizada pelos nativos do litoral paranaense para a cura de odontalgias (Cunico et al., 2005).

Além dos princípios ativos contra a odontalgia, vários dos metabólicos presentes apresentam potencial antifúngico (Cunico et al., 2004). Assim, este estudo analisou o uso do extrato bruto etanólico de O. martiana para o controle de $C$. spathulatum e $B$. cinerea e das doenças causadas por estes fungos.

\section{MATERIAL E MÉTODO}

\section{Obtenção do material vegetal}

Plantas de O. martiana foram coletadas em fevereiro de 2002, no período da manhã, em Coroados, Município de Guaratuba - Paraná, a altitude de 20 metros acima do nível do mar. Aespécie foi identificada pelo botânico Dr. Gerdt Hatschbach, do Museu Botânico Municipal (MBM) da Prefeitura de Curitiba, Paraná. Uma exsicata encontra-se depositada no herbário do MBM sob o número 259.057.

\section{Obtenção do extrato bruto etanólico}

Raízes, caules, folhas e frutos de $O$. martiana (700 g da droga vegetal) foram secas, moídas e submetidas à tripla maceração a frio por sete dias, em solução etanólica a 95\%. Após a maceração, esta solução passou pela filtração, concentração em evaporador rotatório sob pressão reduzida $\left(40^{\circ} \mathrm{C}\right)$, armazenamento em frasco âmbar, conservação em freezer por 24 horas para precipitação de pigmentos e filtração a vácuo. Para a remoção dos solventes utilizados nos processos de extração, particionamento e isolamento, empregou-se evaporador rotatório Büchi, operando à pressão de $30 \mathrm{mmHg}$ e temperatura de $40^{\circ} \mathrm{C}$.

Desse modo, foram obtidos $180 \mathrm{~mL}$ de Extrato Bruto Etanólico (EBEtOH) de O. martiana. Uma parte deste extrato (100 mL) foi reservada para utilização em bioensaios, e a outra $(80 \mathrm{~mL})$ para particionamento pelo processo de partição líquido-líquido (L/L), a frio, utilizando-se funil de separação. A partição foi realizada inicialmente com hexano $(250 \mathrm{~mL})$, seguida por clorofórmio, acetato de etila e metanol, respectivamente, resultando nas frações hexano (FHex - 0,859 g), clorofórmio (FClor - 0,425 g), acetato de etila (FAcOEt - 0,105 g) e metanol (FMeOH - 0,502 g).

A análise qualitativa foi realizada por meio de cromatografia gasosa capilar acoplada à espectrometria de massas (CG-EM, VARIAN com ion trap, modelo 3800/SATURN 2000), com coluna capilar Chrompack de sílica fundida CP-SIL 5 CB (60 m x $0,25 \mathrm{~mm}$ D.I. $\times 1,00 \mu \mathrm{m})$, He como gás de arraste, split 1:100, velocidade linear de $1,6 \mathrm{~mL} \mathrm{~min}^{-1}$. A programação de temperatura na coluna foi de 100 a $300^{\circ} \mathrm{C}$ numa taxa de aquecimento de $10^{\circ} \mathrm{C} \mathrm{min}^{-1}$, permanecendo em $300^{\circ} \mathrm{C}$ por 10 minutos. $\mathrm{O}$ volume de injeção variou entre $0,2-0,5 \mathrm{~mL}$ e a temperatura no injetor foi de $300^{\circ} \mathrm{C}$. As condições no detector foram intensidade de ionização de 70 eV por impacto de elétrons, modulação axial de $6 \mathrm{~V}$, temperaturas de $200^{\circ} \mathrm{C}$ no transferline, $100^{\circ} \mathrm{C}$ no manifold e $150^{\circ} \mathrm{C}$ no ion trap., com faixa de varredura de 20 a 500 m/z.

\section{Avaliação da atividade antifúngica}

Os fitopatógenos $C$. spathulatum e $B$. cinerea utilizados nos ensaios pertencem à coleção 
de fungos patogênicos em espécies florestais da Embrapa Florestas, Colombo, PR.

Para avaliar o potencial antifúngico do EBEtOH de O. martiana, utilizou-se o extrato na concentração de $32,9 \mathrm{mg} \mathrm{mL}^{-1}$. Para determinar o efeito do extrato sobre os fitopatógenos, foram empregados o teste de germinação de esporos (Stangarlin et al., 1999), o teste de patogenicidade em mudas (Quirino et al., 2000) e o teste de bioautografia direta, descrito por Homans \& Fuchs (1970).

\section{Teste de germinação de esporos}

Para o preparo da suspensão de inóculo, culturas monospóricas dos fungos foram utilizadas com a finalidade de diminuir a variabilidade da espécie em estudo. Suspensões de esporos foram preparadas por meio de raspagem superficial das colônias em teste (alça de Drigalski) e transferência para tubos de ensaio com adição de $10 \mathrm{~mL}$ de água esterilizada. A concentração de esporos presentes na suspensão foi avaliada com o auxílio de hemacitômetro e padronizada a concentração de esporos.

O ensaio de germinação de esporos foi feito em placas de Petri. Em cada placa, colocou-se um disco de papel de filtro umedecido com água destilada esterilizada e uma lâmina de vidro para microscopia. Sobre cada lâmina colocou-se três discos de meio BDA (extrato comercial de batata-dextrose, $39 \mathrm{mg}$ $\mathrm{mL}^{-1}$; água destilada, $1000 \mathrm{~mL}$ ) com diâmetro de oito $\mathrm{mm}$ cada. Sobre um disco de meio colocou-se $100 \mu \mathrm{L}$ do EBEtOH (1000 $\left.\mu \mathrm{g} \mathrm{mL}^{-1}\right)$, no outro $100 \mu \mathrm{L}$ do controle negativo de germinação (fungicida comercial $-1000 \mu \mathrm{g} \mathrm{mL}^{-1}$ ) e no último $100 \mu \mathrm{L}$ do controle positivo de germinação (água esterilizada), respectivamente. Posteriormente, foram colocados $100 \mu \mathrm{L}$ da suspensão de esporos de $C$. spathulatum previamente padronizada $\left(1,75 \times 10^{6}\right.$ esporos $\left.\mathrm{mL}^{-1}\right)$ nos discos de meio com os tratamentos. No caso de $B$. cinerea, a suspensão foi padronizada em 1,5 x $10^{6}$ esporos $\mathrm{mL}^{-1}$.

As placas com os discos foram mantidas em câmara BOD na temperatura de $24 \pm 2^{\circ} \mathrm{C}$, por cinco horas de incubação. Após este período, $20 \mu \mathrm{L}$ de lactofenol-azul de metileno foram colocados sobre cada disco de meio, para a leitura final em microscópio ótico. O esporo foi considerado germinado quando o tubo germinativo apresentou comprimento maior ou igual à metade do tamanho do conídio. Foi quantificada a germinação de 100 esporos em quatro quadrantes e no ponto central do disco de meio BDA.

\section{Delineamento estatístico}

O delineamento experimental foi inteiramente casualizado (DIC), com dois tratamentos (fungos), cinco repetições e dois controles. O controle negativo de germinação foi feito com fungicida comercial (benomyl para $C$. spathulatum e iprodione para $B$. cinerea) e o controle positivo de germinação feito com água destilada esterilizada.

\section{Teste de patogenicidade em mudas de erva-mate e eucalipto \\ Quinze mudas de erva-mate ( $I$.} paraguariensis) e de eucalipto (E. dunnii) foram previamente separadas para o bioensaio in vivo, devidamente pulverizadas com água esterilizada. Cinco mudas de cada espécie foram reservadas para o controle positivo de cada doença (pinta-preta e mofo-cinzento). Duas folhas de cada muda foram lesionadas com quatro pequenos furos e pulverizadas com solução do EBEtOH dos órgãos totais de $O$. martiana, a $1000 \mu \mathrm{g} \mathrm{mL}^{-1}$. Como controle negativo, cinco mudas de erva-mate e de eucalipto foram respectivamente pulverizadas com os fungicidas benomyl (pinta-preta) e iprodione (mofo-cinzento), na concentração de $1000 \mu \mathrm{g} \mathrm{mL}^{-1}$. Após 24 horas, discos de papel de filtro esterilizados foram embebidos na suspensão de esporos dos fungos e colocados sobre as folhas lesionadas e dos controles das mudas de erva-mate e eucalipto (dois discos por folha). As concentrações de esporos de C. spathulatum e de $B$. cinerea nas suspensões foram as mesmas do teste de germinação. As mudas foram acondicionadas na casa de vegetação, em caixas plásticas forradas com papel de filtro úmido e esterilizadas.

Após quatorze dias de incubação, fez-se a leitura avaliando-se os sintomas apresentados por cada folha inoculada (escala de avaliação: ausência de sintomas - 0 , infecção leve - 1 , infecção média - 2 , infecção severa - 3 e infecção muito severa -4).

O delineamento experimental foi inteiramente casualizado (DIC), com dois tratamentos (fungos), cinco repetições e dois controles. $O$ controle negativo de crescimento micelial foi feito com fungicida comercial (benomyl para C. spathulatum e iprodione para $B$. cinerea) e o controle positivo de crescimento micelial feito com água destilada esterilizada.

\section{Bioautografia direta}

Buscando-se identificar os constituintes bioativos contra os fitopatógenos, realizou-se investigação por meio de bioautografia direta. Para tal, volumes de $10 \mathrm{~mL}$ do EBEtOH dos órgãos totais $\left(32,9 \mathrm{mg} \mathrm{mL}^{-1}\right)$ e das FHex (1 $\left.\mathrm{mg} \mathrm{mL}^{-1}\right)$, FClor (1 mg $\left.\mathrm{mL}^{-1}\right)$, FAcOEt $\left(1 \mathrm{mg} \mathrm{mL}^{-1}\right)$ e FMeOH $\left(1 \mathrm{mg} \mathrm{mL}^{-1}\right)$, além do controle negativo de crescimento micelial de C. spathulatum (benomyl - $1000 \mu \mathrm{g} \mathrm{mL}^{-1}$ ) e de $B$. cinerea (iprodione - $1000 \mu \mathrm{g} \mathrm{mL}^{-1}$ ) foram aplicados sobre placas de sílica gel $\mathrm{GF}_{254}(2,5 \times 5,0 \mathrm{~cm})$, as quais foram submetidas ao sistema eluente hexano:acetato de etila (70:30), secagem e devidamente acondicionadas em placas de Petri, onde se verteu o meio BDA contendo a suspensão de

Rev. Bras. PI. Med., Botucatu, v.14, n.3, p.464-469, 2012. 
esporos de $C$. spathulatum $\left(1,75 \times 10^{6}\right.$ esporos $\left.\mathrm{mL}^{-1}\right)$ e de $B$. cinerea $\left(1,5 \times 10^{6}\right.$ esporos $\left.\mathrm{mL}^{-1}\right)$, previamente padronizada. Em seguida, as placas foram incubadas em câmara BOD, a $25^{\circ} \mathrm{C}$, na ausência de luz.

Após nítido crescimento dos microorganismos (48 a 72 h), observou-se, quando presentes, a ocorrência de zonas de inibição correspondentes à atividade antifúngica da(s) substância(s) presente(s) em determinado fator de retenção $(R f)$. A detecção dos compostos foi realizada por irradiação com lâmpada de ultravioleta (UV: 366 e $254 \mathrm{~nm}$ ) e posterior revelação com reagente de Dragendorff ou vanilina sulfúrica, seguida de aquecimento (10 $\mathrm{min}$ ).

\section{Delineamento estatístico}

O delineamento experimental foi inteiramente casualizado (DIC), com dois tratamentos (fungos), três repetições e dois controles $\mathrm{O}$ controle negativo de crescimento micelial foi feito com os fungicidas (benomyl e iprodione) e o controle positivo de crescimento micelial feito com água destilada esterilizada. Para a análise estatística dos resultados obtidos, empregou-se o Teste de Tukey, com limite de confiança de $95 \%$, utilizando-se o programa SANEST.

\section{RESULTADO E DISCUSSÃO}

\section{Teste de germinação de esporos}

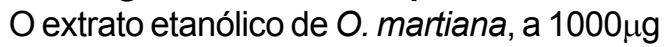
$\mathrm{mL}^{-1}$, apresentou efeitos divergentes sobre a germinação dos fitopatógenos testados. No caso de C. spathulatum, houve inibição da germinação dos esporos, quando comparado ao controle positivo de germinação com água destilada (Tabela 1). Desse modo, o extrato de O. martiana poderia ser empregado como esporostático contra $C$. spathulatum, para promover o controle em mudas de erva-mate.

A inibição da germinação de esporos, com extratos de plantas, é um dos objetivos do biocontrole de doenças de plantas (Parvu et al., 2010). Estes autores estudando o efeito do extrato hidroalcoólico da casca de Berberis vulgaris sobre conídios de $B$. cinerea encontraram mudanças estruturais que levaram à perda da viabilidade. Contudo, este resultado não foi encontrado no presente trabalho e sim aumento na germinação dos conídios, quando comparado com o controle positivo (Tabela 1).

O estímulo da germinação de esporos de $B$. cinerea pelo extrato etanólico de O. martiana indica que este tipo de produto apresenta restrições de uso contra o mofo-cinzento. O estímulo pode ser explicado pela possibilidade de bioativos do EBEtOH em estudo serem utilizadas como nutrientes pelo patógeno. Outra possibilidade está no fato deste fungo ser também saprófita podendo apresentar atividade de biotransformação dos compostos presentes no extrato conduzindo a inibição do efeito fungitóxico (Moreira, 2003). Este efeito estimulador da germinação de $B$. cinerea também foi verificado por Marques et al. (2002), com EBEtOH de folhas e botão floral de Caryocar brasiliense Camb.

Houve, também, baixo percentual de germinação dos esporos de $B$. cinerea no controle positivo, indicando que pode ter ocorrido o fenômeno de auto-inibição decorrente da concentração de esporos testada.

\section{Teste de patogenicidade em mudas de erva-mate e eucalipto}

Os sintomas apresentados pelas mudas de I. paraguariensis e de E. dunnii, após 14 dias da inoculação dos fungos, mostraram que o EBEtOH de O. martiana, na concentração de $1000 \mu \mathrm{g} \mathrm{mL}^{-1}$, não apresentou potencial para o controle das doenças avaliadas (Tabela 2). O tratamento prévio das mudas de erva-mate com EBEtOH de O. martiana promoveu um índice de infecção de $80 \%$, próximo do verificado com as testemunhas inoculadas (90\%). Apesar da inibição da germinação dos esporos de $C$. spathulatum (Tabela 1), o extrato não impediu a penetração nas folhas de erva-mate, indicando que o processo de germinação e penetração deste fungo

TABELA 1. Germinação (\%) de esporos de Cylindrocladium spathulatum e Botrytis cinerea em discos de meio BDA (batata-dextrose-ágar), contendo extrato bruto etanólico (EBEtOH) de Ottonia martiana.

\begin{tabular}{lcccc}
\hline \multirow{2}{*}{ Tratamento } & \multicolumn{2}{c}{ Cylindrocladium spathulatum } & \multicolumn{2}{c}{ Botrytis cinerea } \\
\cline { 2 - 5 } & Germinação(\%) & Inibição(\%) & Germinação(\%) & Inibição (\%) \\
\hline EBEtOH (1000 mg mL-1) & $43,5 \mathrm{a}$ & $56,5 \mathrm{a}$ & $63,0 \mathrm{a}$ & $37,0 \mathrm{a}$ \\
Controle Positivo (água esterilizada) & $100,0 \mathrm{~b}$ & $0,0 \mathrm{~b}$ & $2,5 \mathrm{~b}$ & $97,5 \mathrm{~b}$ \\
Controle Negativo (benomyl) & 0,0 & 100,0 & $\mathrm{NT}$ & $\mathrm{NT}$ \\
Controle Negativo (iprodione) & $\mathrm{NT}$ & $\mathrm{NT}$ & 0,0 & 100,0 \\
\hline
\end{tabular}

*Médias seguidas de mesma letra, nas colunas, não diferem entre si pelo teste de Tukey $(p<0,05)$. Foram considerados germinados aqueles tubos germinativos que apresentassem comprimento $\geq$ à metade do tamanho dos conídios. Controles Negativos $\left(1000 \mu \mathrm{g} \mathrm{mL}^{-1}\right)$. NT = não testado. 
TABELA 2. Número de folhas de mudas de erva-mate e de eucalipto com sintomas, após inoculação com Cylindrocladium spathulatum e Botrytis cinerea, respectivamente, e tratamento com extrato bruto etanólico (EBEtOH) de Ottonia martiana.

\begin{tabular}{lcc}
\hline Tratamento & $\begin{array}{c}\text { Número de folhas } \\
\text { com sintomas }\end{array}$ & $\begin{array}{c}\text { Infecção } \\
\text { (\%) }\end{array}$ \\
\hline Cylindrocladium spathulatum & $1 \mathrm{a}$ & 10 \\
Fungicida (benomyl) & $8 \mathrm{~b}$ & 80 \\
EBEtOH & $9 \mathrm{c}$ & 90 \\
Controle & & \\
Botrytis cinerea & $1 \mathrm{a}$ & 10 \\
Fungicida (iprodione) & $10 \mathrm{~b}$ & 100 \\
EBEtOH & $9 \mathrm{c}$ & 90 \\
Controle & 9
\end{tabular}

*Médias seguidas de mesma letra, nas colunas, não diferem entre si pelo teste de Tukey $(P<0,05)$. Inoculação de Cylindrocladium spathulatum em dez folhas de erva-mate e de Botrytis cinerea em dez folhas de eucalipto.

podem ser mais rápidos e mediados por outros fatores, diferentemente do que existe em meio de cultura.

As mudas de eucalipto previamente tratadas com o EBEtOH, apresentaram índice de infecção $(100 \%)$ maior que o das testemunhas inoculadas $(90 \%)$, indicando que o também não apresenta potencial para o controle do mofo-cinzento, inclusive com possibilidade de estimular o desenvolvimento do mesmo.

Os resultados deste bioensaio indicam que o controle da pinta-preta em erva-mate, assim como do mofo-cinzento em eucalipto não é viável com EBEtOH de O. martiana, na concentração de $1000 \mu \mathrm{g} \mathrm{mL}^{-1}$. No caso do mofo-cinzento, a aplicação do extrato de $O$. martiana estimulou a formação de lesões algo similar ao estímulo à germinação de esporos verificado no teste de germinação de $B$. cinerea (Tabela 1). Esse estímulo à germinação pode ter resultado em maior quantidade de doença.

Os resultados dos ensaios in vitro sugerem que o EBEtOH de O. martiana teria ação somente sobre o desenvolvimento vegetativo destes fitopatógenos. Normalmente, em ensaios de fungicidas faz-se a avaliação do efeito de controle em dosagens que vão de zero a $1000 \mu \mathrm{g} \mathrm{mL}^{-1}$. No caso de produtos químicos que necessitem de concentrações além de $1000 \mu \mathrm{g} \mathrm{mL}^{-1}$, potencial e a viabilidade para uso em controle químico torna-se questionada por causa da grande quantidade de produto que terá de ser aplicada sobre as plantas hospedeiras.

Estudos complementares com concentrações superiores a $1000 \mu \mathrm{g} \mathrm{mL}^{-1}$ devem ser realizados, visto que as substâncias bioativas presentes neste EBEtOH podem ser dose-dependentes. Outro aspecto é o tipo de extrato utilizado, pois estudo de Camatti-Sartori et al. (2011) mostrou que o extrato acético causou maior inibição do crescimento micelial de Botrytis sp. do que o extrato etanólico.

\section{Bioautografia direta}

Este bioensaio permitiu detectar zonas de inibição de crescimento do fungo $C$. spathulatum de acordo com o fator de retenção ( $R f \mathrm{~s}=0,2 ; 0,35$ e $0,6)$ nos bioautogramas contendo EBEtOH, frações FHex e FClor. Outro estudo de bioautografia direta com EBEtOH de Aster lanceolatus Willd. também mostrou a presença de compostos que causam a inibição do crescimento desse fungo (Dias et al., 2006). No caso de B. cinerea somente uma zona de inibição foi detectada nos bioautogramas contendo EBEtOH e FHex $(R f=0,35)$.

As zonas de inibição com diferentes fatores de retenção sugerem a presença de vários componentes bioativos no EBEtOH da espécie em estudo. Contudo, tanto para C. spathulatum como para $B$. cinerea, houve um fator de retenção comum para a inibição $(R f=0,35)$. Em seguida, buscouse identificar os componentes bioativos deste extrato, com relação a este fator de retenção, procedendo-se a raspagem das zonas de inibição nas cromatoplacas por meio de CG-EM, comparação com dados de literatura, amostra autêntica e biblioteca eletrônica NIST. Esta, pela análise por CG-EM, apresentou íon molecular $\mathrm{m} / \mathrm{z}$ $273\left([\mathrm{M}]^{\circ}, 58 \%\right)$ e os fragmentos $201(7 \%), 173$ $(100 \%), 159(48 \%), 152(76 \%), 139(35 \%), 121$ $(18 \%), 115(27 \%), 96(49 \%)$. Os dados dos espectros de massas juntamente com o ponto de fusão $\left(115-119^{\circ} \mathrm{C}\right)$ foram compatíveis com aqueles descritos na literatura para a piperovatina (Costa \& Mors, 1981; Facundo et al., 2004; Cunico et al., 2004; Cunico et al., 2007).

Os metabólitos secundários de espécies da família Piperaceae apresentam atividade antifúngica, tais como as amidas piperovatina e piperlonguminina 
(Parmar et al., 1997), confirmado nesse estudo com os fungos estudados.

\section{CONCLUSÃO}

Os resultados dos testes antifúngicos sugerem que o EBEtOH dos órgãos totais de $O$. martiana podem apresentar potencial antifúngico in vitro em função do fitopatógeno estudado. Houve inibição da germinação de esporos de $C$. spathulatum enquanto que o extrato estimulou a germinação de esporos de $B$. cinerea.

O extrato bruto etanólico dos órgãos totais, na concentração de 1000 ppm não apresentou potencial para o controle das doenças avaliadas. Em mudas de erva-mate, não houve potencial para o controle da pinta-preta e nas mudas de eucalipto, houve estímulo ao desenvolvimento do mofo-cinzento.

O potencial antifúngico deste extrato sobre o desenvolvimento vegetativo dos fitopatógenos estudados foi investigado para identificar os constituintes bioativos do mesmo por bioautografia direta, pela qual foram detectadas zonas de inibição de crescimento micelial dos fungos, permitindo identificar uma das substâncias bioativas: a piperovatina.

\section{REFERÊNCIA}

BARBOSA, F.S. et al. Métodos de extração e concentrações no efeito inseticida de Ruta graveolens L., Artemisia verlotorum Lamotte e Petiveria alliacea L. a Diabrotica speciosa Germar. Revista Brasileira de Plantas Medicinais, v.11, n.3, p.221-39, 2009.

CAMATTI-SARTORI, V. et al. Avaliação in vitro de extratos vegetais para o controle de fungos patogênicos de flores. Revista Brasileira de Agrobiologia, v.6, n.2, p.117-22, 2011.

COSTA, S.S.; MORS, W.B. Amide of Ottonia corcovadensis. Phytochemistry, v.20, n.6, p.1305-7, 1981.

CUNICO, M.M. et al. Avaliação antifúngica de extratos obtidos de Ottonia martiana Miq. (Piperaceae) sobre três fitopatógenos. Arquivos do Instituto Biológico, v.71, p.141-3, 2004.

CUNICO, M.M. et al. Gênero Ottonia: uma revisão das principais características botânicas, fitoquímicas e biológicas. Revista Brasileira de Plantas Medicinais, v.7, n.2, p.17-21, 2005.

CUNICO, M.M. et al. Phytochemical and antibacterial evaluation of essential oils from Ottonia martiana Miq. Journal of the Brazilian Chemical Society, v.18, p.1848, 2007.

DIAS, J.F.G. et al. Atividade antibacteriana e antifúngica de extratos etanólicos de Aster lanceolatus Willd., Asteraceae. Revista Brasileira de Farmacognosia, v.16, n.1, p.83-7, 2006.

FACUNDO, V.A.; MORAIS, S.M.; BRAZ FILHO, R.
Constituintes químicos de Ottonia corcovadensis Miq. da floresta Amazônica: atribuição dos deslocamentos químicos dos átomos de hidrogênio e carbono. Química Nova, v.27, n.1, p.79-83, 2004.

FERREIRA, A.G.; ROSA, S.G.T. Germinação de sementes de sete espécies medicinais nativas do sul do Brasil. Revista Brasileira de Plantas Medicinais, v.11, n.3, p.230-5, 2009.

GRIGOLETTI JUNIOR; A.; AUER, C.G. Doenças da ervamate. In: KIMATI, H. et al. (Eds.). Manual de fitopatologia: doenças das plantas cultivadas. 4.ed., São Paulo: Agronômica Ceres, 2005. v.2, p.309-10.

HOMANS, A.L.; FUCHS, A. Direct bioautography on thinlayer chromatograms as a method for detecting fungitoxic substances. Journal of Chromatography, v.51, p.32730, 1970.

KRUGNER, T.L.; AUER, C.G. Doenças em eucaliptos. In: $\mathrm{KIMATI}, \mathrm{H}$. et al. (Eds.). Manual de fitopatologia: doenças das plantas cultivadas. 4.ed., São Paulo: Agronômica Ceres, 2005, v.2. p.319-32.

MACIEL, M.A.M. et al. Plantas medicinais: a necessidade de estudos multidisciplinares. Química Nova, v.25, n.3, p.429-38, 2002.

MARQUES, M.C.S. et al. Efeito fungitóxico dos extratos de Caryocar brasiliense Camb. sobre os fungos Botrytis cinerea, Colletotrichum truncatum e Fusarium oxysporum. Ciência e Agrotecnologia, v.26, ed. especial, p.1410-9, 2002.

MOREIRA, C.G.A. Caracterização parcial de frações eliciadoras presentes em extratos de Cymbopogon nardus. 2003. 51p. Dissertação (Mestrado em Agronomia) - Universidade Estadual de Maringá, Maringá.

PARMAR, V.S. et al. Phytochemistry of the genus Piper. Phytochemistry, v.46, n.4, p.597-673, 1997.

PARVU, M. et al. Changes in Botrytis cinerea conidia caused by Berberis vulgaris extract. Notula Botanicae Horticulturae Agrobotanicae, v.38, n.3, p.15-20, 2010. QUIRINO, V.F. et al. Efeito do extrato aquoso de folhas de seis espécies florestais sobre a germinação e crescimento micelial de Cylindrocladium spathulatum e Colletotrichum sp. Summa Phytopathologica, v.26, n.1, supl., p.141-3, 2000.

SANTOS, F.S. et al. Efeito de extratos vegetais no progresso de doenças foliares do cafeeiro orgânico. Fitopatologia Brasileira, v.32, n.1, p.59-63, 2007.

SCHWAN ESTRADA, K.R.F.; STANGARLIN, J.R.; CRUZ, M.E.S. Uso de plantas medicinais no controle de doenças de plantas. Fitopatologia Brasileira, v.28, supl., p. 5546, 2003.

SILVA, A.C. et al. Efeito in vitro de compostos de plantas sobre o fungo Colletotrichum gloeosporioides Penz. isolado do maracujazeiro. Ciência e Agrotecnologia, v.33, edição especial, p.1853-60, 2009.

STANGARLIN, J.R. et al. Plantas medicinais e controle alternativo de fitopatógenos. Biotecnologia: Ciência \& Desenvolvimento, v.2, n.11, p.16-21, 1999.

VIGO, S.C. et al. Ação de tinturas e óleos essenciais de plantas medicinais sobre o crestamento bacteriano comum do feijoeiro e na produção de proteínas de indução de resistência. Summa Phytopathologica, v.35, n.4, p.293-304, 2009.

Rev. Bras. PI. Med., Botucatu, v.14, n.3, p.464-469, 2012. 